\title{
Efficacy of under-gel endoscopic mucosal resection method for colonic lesion extending into the diverticulum
}

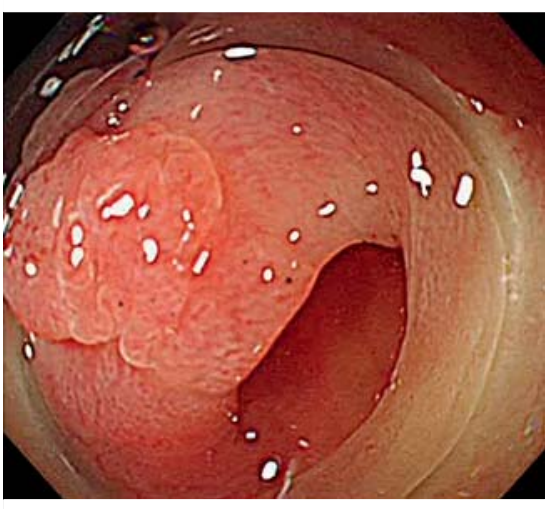

- Fig. 1 A protruded lesion extending into the diverticulum was seen in the ascending colon.

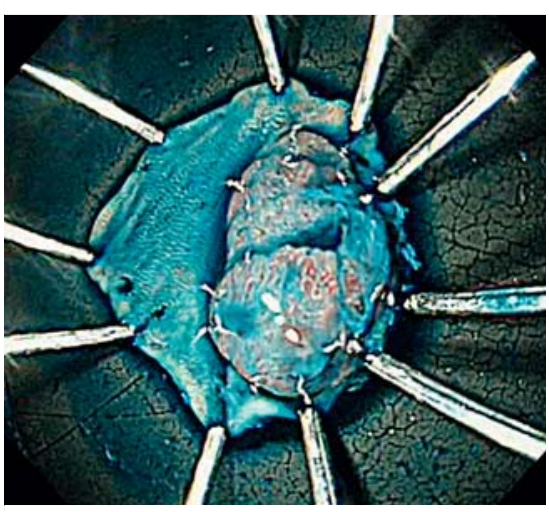

- Fig. 4 A negative horizontal margin was confirmed.

Underwater endoscopic mucosal resection (EMR) is currently performed in various situations [1-4]. One advantage to using water is the buoyancy effect on the mucosa, which raises it from the deeper muscularis propria without submucosal injection [1]. However, it takes time to fill the intestinal tract with water, leading to an increased risk of peristalsis and abdominal distension. In addition, underwater EMR on lesions extending into narrow spaces can be difficult to snare because constant water pressure is required. Here, we present a case in which a colonic adenoma extending into the

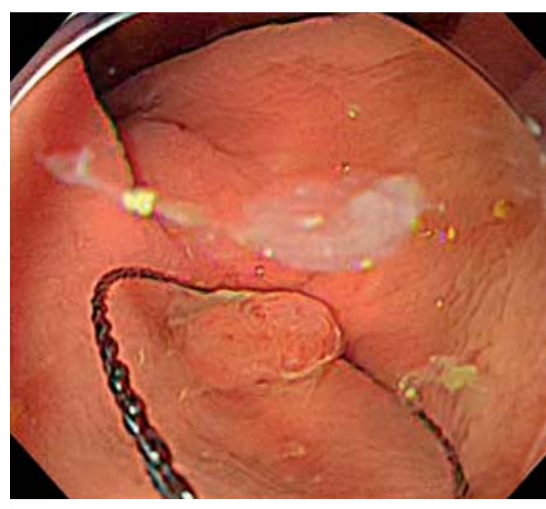

Fig. 2 We set the tip of the snare on the end of the diverticulum under gel.

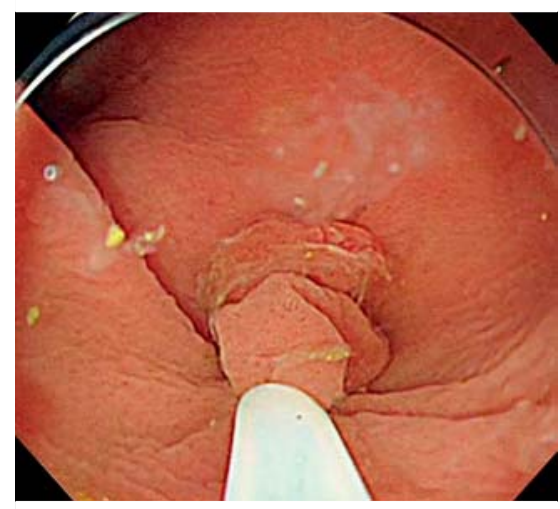

- Fig. 3 The lesion was successfully resected en bloc using under-gel endoscopic mucosal resection.

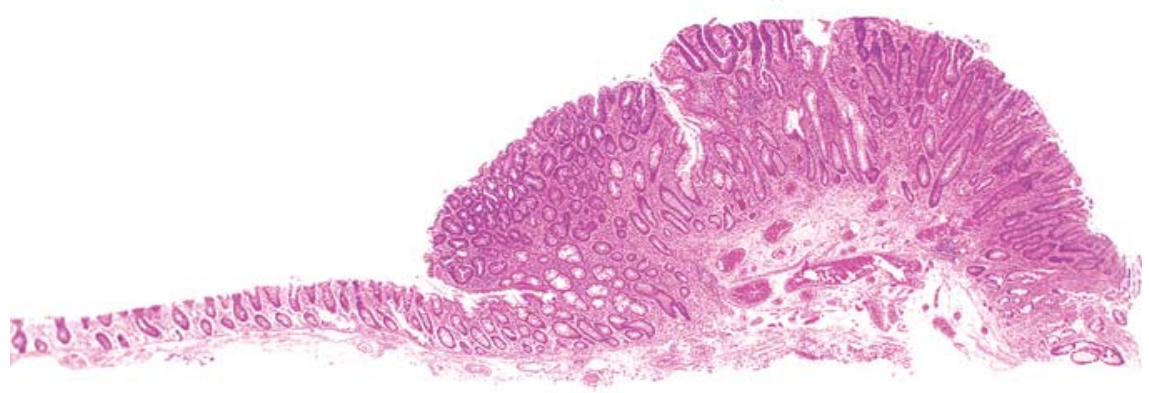

- Fig. 5 The pathological result was high grade dysplasia with a negative margin.

diverticulum was successfully resected using "under-gel EMR" via VISCOCLEAR, a gel product for endoscopic procedures (Otsuka Pharmaceutical Factory, Tokushima, Japan).

A 77-year-old man presented with a protruded lesion extending into the diverticulum; it was approximately $10 \mathrm{~mm}$ in size and located in the ascending colon (> Fig.1). Submucosal saline injection was difficult; therefore, we sought to perform under-gel EMR ( $\triangleright$ Video 1). We used a PCF Q260JI colonoscope (Olympus Medical Systems, Tokyo, Japan) with approximately $100 \mathrm{ml}$ of VISCOCLEAR. Sufficient buoyancy for excision and visualization of the lesion margin extending to the diverticulum was confirmed under gel; therefore, snaring was performed using the SnareMaster (10 mm; Olympus Medical Systems) (> Fig.2, > Fig.3). A highfrequency electrical generator (VIO 3; Erbe Elektromedizin, Tübingen, Germany) was used with ENDO CUT Q settings. We successfully resected the lesion en bloc and closed the mucosal defect with clips (> Fig.4). The pathological result was high grade dysplasia with a negative margin ( $\mathbf{F i g . 5}$ ).

Under-gel EMR does not require filling the lumen, so it takes less time and results in less peristalsis and distension. In addition, snaring of lesions is easier in narrow spaces, such as the diverticula, 


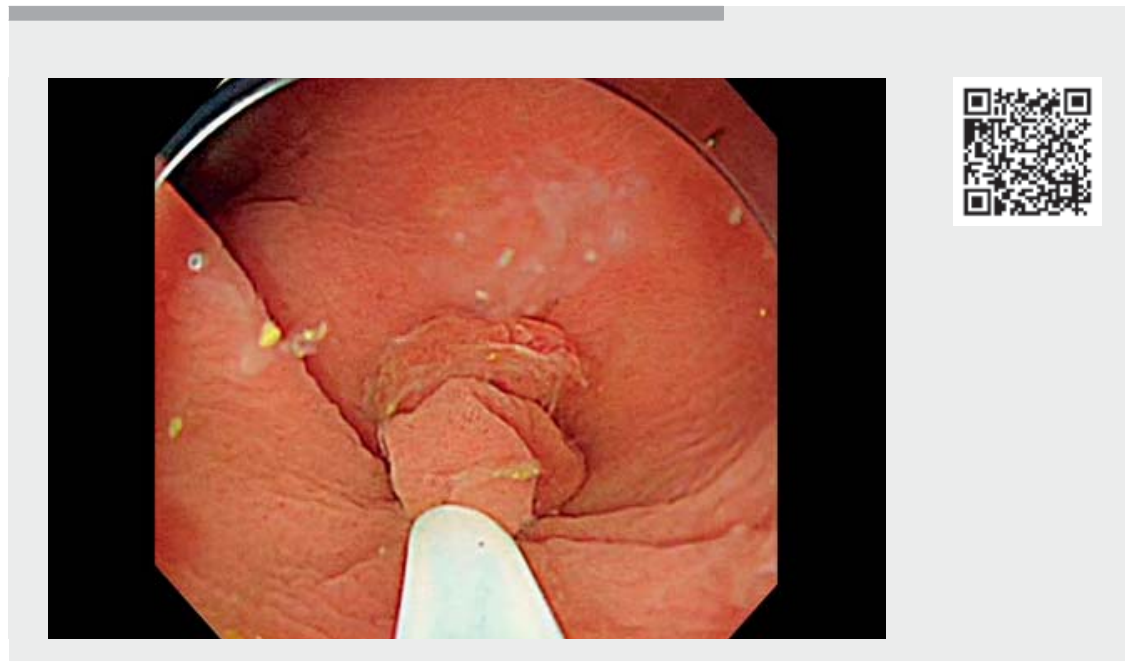

$\checkmark$ Video 1 Under-gel endoscopic mucosal resection method for a colonic lesion extending into the diverticulum.

because constant water pressure is not required. This new treatment has the potential to be useful and effective for colorectal tumors.

Endoscopy_UCTN_Code_TTT_1AQ_2AD

Competing interests

The authors declare that they have no conflict of interest.

The authors

\section{Hiroki Kuwabara 9 Hideyuki Chiba $९$ Jun Tachikawa, Naoya Okada, Jun Arimoto, Michiko Nakaoka}

Omori Red Cross Hospital, Department of Gastroenterology, Tokyo, Japan
Corresponding author

\section{Hideyuki Chiba, MD, PhD}

Department of Gastroenterology, Omori Red Cross Hospital, 4-30-1 Chuo, Ota-ku, Tokyo 143-0024, Japan Fax: +81-3-3776-0004 h.chiba04@gmail.com

\section{References}

[1] Binmoeller KF, Weilert F, Shah J et al. "Underwater" EMR without submucosal injection for large sessile colorectal polyps (with video). Gastrointest Endosc 2012; 75: 1086 1091

[2] Shichijo S, Yamaguchi Y, Nakahara M et al. Underwater EMR of a colonic adenoma surrounded by diverticula. Video GIE 2020; 5 : 157-158

[3] Binmoeller KF, Hamerski CM, Shah JN et al. Underwater EMR of adenomas of the appendiceal orifice (with video). Gastrointest Endosc 2016; 83: 638-642

[4] Yamashina T, Uedo N, Akasaka T et al. Comparison of underwater vs conventional endoscopic mucosal resection of intermediate-size colorectal polyps. Gastroenterology 2019; 157: 451-461

\section{Bibliography}

Endoscopy 2022; 54: E292-E293

DOI 10.1055/a-1519-6642

ISSN 0013-726X

published online 2.7.2021

(c) 2021. Thieme. All rights reserved.

Georg Thieme Verlag KG, Rüdigerstraße 14, 70469 Stuttgart, Germany

\section{ENDOSCOPY E-VIDEOS}

https://eref.thieme.de/e-videos 